\title{
Analisis Pemilihan Guru Konseling dengan Metode VIKOR pada SMK TPI Alhasanah Pematang Bandar
}

\author{
Delima Syah Putri Sinaga ${ }^{1}$, Sundari Retno Andani' ${ }^{2}$, Dedi Suhendro ${ }^{2, *}$ \\ ${ }^{1}$ STIKOM Tunas Bangsa, Pematangsiantar, Sumatera Utara, Indonesia \\ ${ }^{2,3}$ AMIK Tunas Bangsa, Pematangsiantar, Sumatera Utara, Indonesi \\ Jln. Sudirman Blok A No. 1-3 Pematangsiantar, Sumatera Utara \\ Email: 1delimassinaga@gmail.com, ${ }^{2}$ sundar.ra@amiktunasbangsa.ac.id, ${ }^{3}$ dedishu16@gmail.com \\ Submitted: 08/11/2021; Accepted: 15/11/2021; Published: 30/11/2021
}

\begin{abstract}
Abstrak-Penelitian ini bertujuan untuk menentukan guru konseling yang tepat di SMK TPI Al-Hasanah agar dapat membantu, mengarahkan dan mengubah prilaku menyimpang para siswa yang terjadi di dilingkungan sekolah. Sistem pendukung keputusan yang diterapkan pada penelitian ini yaitu dengan menggunakan metode VIKOR. Data yang diperoleh pada penelitian ini dengan cara melakukan observasi langsung ke lapangan dan juga meminta data yang akurat kepada pimpinan. Pemiliha guru konseling dilakukan dengan beberapa kriteria. Adapun kriteria nya adalah : (K1) tamatan terakhir, (K2) Lama Bekerja, (K3), Kedisiplinan, (K4) Sertifikat pendukung. Diharapkan hasil penelitian dengan metode VIKOR ini dapat menetukan guru guru konseling ang tepat dan mampu mengarahkan siswa di SMK TPI Al-Hasanah mejadi pribadi yang lebih berahlak baik di lingkungan sekolah dan juga masyarakat.
\end{abstract}

Kata Kunci: Pemilihan Guru Konseling; VIKOR; Konseling; Sistem Pendukung Keputusan

\begin{abstract}
This study aims to determine the right counseling teacher at SMK TPI Al-Hasanah to be able to help, direct and change the deviant behavior of students that occur in the school environment. The decision support system applied in this study is by using the VIKOR method. The data obtained in this study by direct observation to the field and also requesting accurate data from the leadership. The selection of counseling teachers is done with several criteria. The criteria are: (K1) last graduation, (K2) Length of Work, (K3), Discipline, (K4) Supporting certificates. It is expected that the results of this research using the VIKOR method can determine appropriate counseling teachers and be able to direct students at SMK TPI AlHasanah to become more virtuous individuals both in the school environment and also in the community.
\end{abstract}

Keywords: Selection of Counseling Teachers; VIKOR; Counseling; Decision Support System

\section{PENDAHULUAN}

Sistem Pendukung Keputusan (SPK) adalah sebuah sistem yang dapat membantu dan mendukung suatu instansi ataupun perusahaan dalam mengambil sebuah keputusan untuk memecahkan masalah - masalah baik itu yang bersifat semi terstruktur maupun juga terstruktur. Dalam bahasa ingris sitem informasi disebut dengan DSS yang berarti Decision Support System [1], [2]. Dari beberapa metode yang ada pada Sistem Pendukung Keputusan maka peneliti menggunakan metode VIKOR. VIKOR adalah singkatan dari VIsekriterijumsko KOmpromisno Rangiranje.Metode VIKOR adalah salah satu metode yang tepat pada penelitian kali ini, sebab didasarkan pada perangkingan.VIKOR berfokus kepada perangkingan dalam mengkompromikan dari hasil alternative dan kriteria - kriteria yang bertentangan [3]-[7].

Beberapa peneliti terdahulu menerapkan Metode VIKOR dalam riset yang telah dilakukan seperti [3] dalam riset nya yang menjelaskan tentang penerapan metode VIKOR dalam pemilihan calon peserta olimpiade olahraga siswa nasional (O2SN). Pada penelitian ini penulis juga menerapkan metode VIKOR dalam memilih guru konseling terhususnya SMK TPI AL-HASANAH Pematang Bandar. Dilakukannya pemilihan guru konseling diakibatkan kurangnya etika yang terjadi di kalangan anak pada saat ini membuat pihak sekolah semakin perihatin dengan keadaan anak saat ini. Sehingga peranan guru bimbingan konseling itu sangat dibutuhkan pada setiap siswa yang membutuhkan arahan dari prilaku menyimpang tersebut.

Dalam pemillihan guru konseling sistem pendukung keputusan VIKOR dapat digunakan baik itu yang bersift kuantitatif maupun kualitatif. Dengan diterapkannya metode VIKOR, diharapkan dapat menghasilkan suatu keputusan yanng tepat dalam merekomendasikan guru konseling di SMK TPI Al-Haanah Pematang Bandar.

\section{METODOLOGI PENELITIAN}

Dalam penulisan ini, adanya metodologi penelitian yang digunakan sebagai tahapan-tahapan atau langkahlangkah untuk menyelesaikan permasalahan dalam penelitian ini adalah metode penelitian kuantitatif yang menuntut lebih banyak terhadap penggunaan angka-angka. Data penelitian dikumpulkan melalui proses pengumpulan data yang di beri oleh kepala sekolah SMK TPI Al-Hasanah Pematang Bandar yang dapat dijadikan kritera dalam pemilihan guru konseling di SMK TPI Al-Hasanah Pematang Bandar. Maka dari itu instrumen penelitian yang digunakan mempunyai ukuran yang akurat. Dalam proses penyelaian yang dilakukan, di gunakan system pendukung keputusang menggunakan metode VIKOR. 


\subsection{Sistem Pendukung Keputusan}

Sistem pendukung keputusan (SPK) adalah bagian dari sistem informasi berbasis komputer termaksud sistem berbasis pengetahuan yang dipakai untuk mendukung suatu pengambilan keputusan yang dipakai oleh suatu instansi aatu suatu perusahaan. Sistem pendukung keputusan juga dapat dikatan sebagai bahan pemecahan masaklah baik itu yang memiliki data informasi dalam mengambil sebuah keputusan [8]-[10].

\subsection{Metode VIKOR}

Metode VIKOR adalah salah satumetode pengambilan keputusan multi kriteria atau biasa dikenal dengan MCDM, metode VIKOR berfokus kepada penentuan peringkatdan pemilihan dari sekumpulan alternatif kriteria yang saling bertentangan [3][11]. Langkah-langkah yang digunakan dalam metode VIKOR adalah sebagai berikut:

a) Membuat matriks keputusan (F)

Dari data yang didapat dijadikan data untuk matriks Keputusan F). Pada langkah ini setiap kriteria dan alternatif disusun ke dalam bentuk matriks $\mathrm{F}$; Aj menyatakan alternatif ke $\mathrm{i}=1,2,3, \ldots \mathrm{m}$; dan $\mathrm{Cxn}$ menyatakan kriteria ke $\mathrm{j}=1,2,3, \ldots \mathrm{n}$.

$$
\left.\mathrm{F}=\stackrel{A_{1}}{A_{2}} \begin{array}{cccc}
C_{x 1} & C_{x 2} \cdots & C_{x n} \\
x_{11} & x_{12} \cdots & x_{1 n} \\
A_{m} & x_{2} \cdots & x_{2 n} \\
x_{21} & \vdots & \vdots & \vdots \\
x_{m 1} & x_{m 2} \cdots & x_{m n}
\end{array}\right]
$$

Keterangan :

Xij : Respon alternatif i pada kriteria $\mathrm{j}$

I $\quad: 1,2,3, \ldots, \mathrm{m}$ adalah nomor urutan alternative

$\mathrm{J} \quad: \quad: 1,2,3, \ldots, \mathrm{n}$ adalah nomor urutan atribut atau criteria

Ai : Alternatif ke $-\mathrm{i}$

$\mathrm{Cj} \quad$ : Kriteria $\mathrm{ke}-\mathrm{j}$

F : Matriks Keputusan

b) Menentukan bobot kriteria (W)

Menentukan bobot kriteria yang diperoleh dari pengguna sistem sesuai dengan kebutuhan atau kriteria yang diinginkan. Rumusan umum untuk bobot kriteria adalah berlaku persamaan:

$\sum_{j=1}^{n} W_{j=1}$

Keterangan :

Wj : bobot kriteria $\mathrm{j}$

J $\quad: 1,2,3, \ldots, \mathrm{n}$ adalah nomor urutan atribut atau kriteria

c) Membuat matriks normalisasi $(\mathrm{N})$

Membuat matriks normalisasi dengan menentukan nilai positif dan nilai negatif sebagai solusi ideal dari setiap kriteria.Matrik F tersebut kemudian di normalisasikan dengan persamaan sebagai berikut:

$N_{i j}=\frac{\left(f_{j}^{+}-f_{i j}\right)}{\left(f_{j}^{+}-f_{j}^{-}\right)}$

Keterangan :

$$
\begin{array}{ll}
\text { fij } & \text { : Fungsi respon alternatif i pada kriteria } \mathrm{j} \\
\mathrm{f}+\mathrm{j} & : \text { nilai terbaik/positif dalam satu kriteria } \mathrm{j} \\
\mathrm{f}-\mathrm{j} & : \text { nilai terjelek/negatif dalam satu kriteria } \mathrm{j} \\
\mathrm{i} & : 1,2,3, \ldots, \mathrm{m} \text { adalah nomor urutan alternative } \\
\mathrm{j} & : 1,2,3, \ldots, \mathrm{n} \text { adalah nomor urutan atribut atau criteria } \\
\mathrm{N} & : \text { Matriks Ternormalisasi }
\end{array}
$$

Penentuan nilai data terbaik/positif $(\mathrm{f}+\mathrm{j})$ dan terburuk/negatif ( $\mathrm{f}-\mathrm{j})$ atau dengan istilah Cost dan Benefit dalam satu variabel penelitian ditentukan oleh jenis data variabel penelitian higher-the-better (HB) atau lower-the-better $(\mathrm{LB})$. Nilai $(\mathrm{f}+\mathrm{j})$ dan $(\mathrm{f}-\mathrm{j})$ tersebut dinyatakan sebagai berikut:

$f_{j}=\max \left(f_{1 j}, f_{2 j}, f_{3 j}, \ldots, f_{m j}\right)$

$f_{j}=\min \left(f_{1 j}, f_{2 j}, f_{3 j}, \ldots, f_{m j}\right)$

Keterangan :

$\mathrm{f}+\mathrm{j} \quad$ : nilai terbaik/positif dalam satu kriteria $\mathrm{j}$

$\mathrm{f}-\mathrm{j} \quad$ : nilai terjelek/negatif dalam satu kriteria $\mathrm{j}$

i $\quad: 1,2,3, \ldots, \mathrm{m}$ adalah nomor urutan alternative

$\mathrm{j} \quad: 1,2,3, \ldots, \mathrm{n}$ adalah nomor urutan atribut atau kriteria

d) Normalisasi bobot $\left(\mathrm{F}^{*}\right)$

Melakukan perkalian antara nilai data yang telah dinormalisasi (N) dengan nilai bobot kriteria (W) yang telah ditentukan, dengan perhitungan sebagai berikut: 


$$
F_{i j}^{*}=w_{j} \cdot N_{i j}
$$

Keterangan :

$\mathrm{F}^{*} \mathrm{ij} \quad$ : Nilai data ternormalisasi yg sudah terbobot untuk alternatif i pada kriteria $\mathrm{j}$

wj : nilai bobot pada kriteria $\mathrm{j}$

Nij $\quad$ : nilai data ternormalisasi untuk alternatif $\mathrm{i}$ pada kriteria $\mathrm{j}$

i $\quad: 1,2,3, \ldots, \mathrm{m}$ adalah nomor urutan alternative

$\mathrm{j} \quad: 1,2,3, \ldots, \mathrm{n}$ adalah nomor urutan atribut atau kriteria

Menghitung utility measures $(\mathrm{S})$ dan regret measures $(\mathrm{R})$

Utility measures (S) dan Regret measures ( $\mathrm{R}$ ) dari setiap alternatif dihitung menggunakan rumus sebagai berikut:

$S_{i}=\sum_{j=1}^{n} W_{j}\left[\frac{\left(f_{j}^{+}-f_{i j}\right)}{\left(f_{j}^{+}-f_{j}^{-}\right)}\right]$

$\mathrm{S}_{\mathrm{i}} \quad$ :Merupakan jarak Manhattan (Manhattan distance) yang terbobot dan dinormalisasi.

$R_{i}=\max _{j}\left[\frac{\left(f_{j}^{+}-f_{i j}\right)}{\left(f_{j}^{+}-f_{j}^{-}\right)}\right]$

$\mathrm{R}_{\mathrm{i}}$ : merupakan jarak Chebyshev (Chebyshev distance) yang terbobot dan dinormalisasi.

$\mathrm{S}_{\mathrm{i}}$ : (maximum group utility) dan

$\mathrm{R}_{\mathrm{i}}$ (minimum individual regret of the opponent), keduanya menyatakan utility measures yang diukur dari titik terjauh dan titik terdekat dari solusi ideal, sedangkan wj adalah bobot yang diberikan pada setiapkriteria ke-j

e) Menghitung indeks VIKOR (Q)

Setiap alternatif i dihitung indeks VIKOR-nya menggunakan rumus sebagai berikut :

$Q_{i}=v\left[\frac{\left(S_{i}-S^{+}\right)}{\left(S^{+}-S^{-}\right)}\right]+(1-v)\left[\frac{\left(R_{i}-R^{+}\right)}{\left(R^{+}-R^{-}\right)}\right]$

$\mathrm{S}^{-}: \min _{\mathrm{i}}\left(\mathrm{S}_{\mathrm{i}}\right)$

$\mathrm{S}^{+}: \max _{\mathrm{i}}\left(\mathrm{S}_{\mathrm{i}}\right)$

$\mathrm{R}^{-}: \min _{\mathrm{i}}\left(\mathrm{R}_{\mathrm{i}}\right)$

$\mathrm{R}^{+}: \max _{\mathrm{i}}\left(\mathrm{R}_{\mathrm{i}}\right)$

$\mathrm{v}: \mathrm{v}$ adalah veto yaitu rule dari metode VIKOR digunakan untuk menghitung indeks VIKOR yang bernilai 0,$4 ; 0,5$ atau 0,6 . Semakin kecil nilai indeks VIKOR $\left(\mathrm{Q}_{\mathrm{i}}\right)$ maka semakin baik pula solusialternatif tersebut.

f) Perangkingan alternatif

Pada metode VIKOR perangkingan alternatif dilihat berdasarkan nilai indeks VIKOR yang telah dicari dimana alternatif yang memiliki indeks VIKOR dengan nilai terkecil adalah alternatif yang paling efektif dan menduduki peringkat pertama.

\section{HASIL DAN PEMBAHASAN}

Data penelitian terdiri dari 5 alternatif dan 6 kriteria yang diperoleh dari hasil wawancara seperti yang tertera pada tabel 1.

Tabel 1. Data Penelitian

\begin{tabular}{lllllll}
\hline \multicolumn{1}{c}{ Alternatif } & \multicolumn{1}{c}{ Tamatan } \\
& Terakhir & $\begin{array}{c}\text { Lama } \\
\text { Bekerja }\end{array}$ & \multicolumn{1}{c}{ Kedisiplinan } & $\begin{array}{c}\text { Sertifikat } \\
\text { Pendukung }\end{array}$ & Absensi & Prestasi \\
& Starata Satu & Baik & Sangat Baik & Baik & Baik & Baik \\
Sukron Hutagaol & Starata Satu & Cukup & Baik & Cukup & Cukup & Cukup \\
Surya Dermawan & Starata Satu & Baik & Baik & Cukup & Baik & Baik \\
Raimah & Starata Satu & Baik & Baik & Sangat Baik & Baik & Baik \\
Kustini Asih & Starata Satu & Cukup & Sangat Baik & Cukup & Baik & Cukup \\
Mensi Sriwahyuni & & & & & & \\
\hline
\end{tabular}

Selanjutnya masuk dalam tahap perhitungan menggunakan metode VIKOR dengan data yang telah dikonversi terlebih dahulu C1: Tamatan Terakhir, C2: Lama Bekerja, C3: Kedisplinan, C4: Sertifikat Pendukung, C5: Absensi, C6: Prestasi.

Tabel 2. Data Konversi

\begin{tabular}{cccccccc}
\hline No & Alternatif & C1 & C2 & C3 & C4 & C5 & C6 \\
\hline 1 & Sukron Hutagaol & 2 & 3 & 1 & 3 & 3 & 2 \\
2 & Surya Dermawan & 3 & 2 & 1 & 4 & 2 & 3 \\
3 & Raimah & 1 & 3 & 1 & 3 & 3 & 2 \\
4 & Kustini Asih & 3 & 3 & 2 & 4 & 3 & 2
\end{tabular}


Journal of Computer System and Informatics (JoSYC)

Volume 3, No. 1, November 2021, Page 9-15

ISSN 2714-8912 (media online)

ISSN 2714-7150 (media cetak)

DOI 10.47065/josyc.v3i1.951

\begin{tabular}{llllllll}
5 & Mensi Sriwahyuni & 4 & 2 & 2 & 2 & 3 & 3 \\
\hline
\end{tabular}

\subsection{Penerapan Metode VIKOR}

a) Menentukan nilai maksimum dan minimum dari masing-masing kriteria dari seluruh alternatif.

Tabel 3. Nilai Maksimum dan Minimum

\begin{tabular}{ccccccc}
\hline Nilai & C1 & C2 & C3 & C4 & C5 & C6 \\
\hline Max & 4 & 3 & 2 & 4 & 3 & 3 \\
Min & 1 & 2 & 1 & 2 & 2 & 2 \\
\hline
\end{tabular}

b) Melakukan normalisasi matriks dengan menggunakan persamaan (1), dan berikut adalah proses normalisasi matriks.

$$
\begin{aligned}
& \text { Kriteria Lama Bekerja : } \\
& \text { Sukron Hutagaol }=\frac{3-3}{3-2}=0 \\
& \text { Surya Dermawan }=\frac{3-2}{3-2}=1 \\
& \text { Raimah }=\frac{3-3}{3-2}=0 \\
& \text { Kustini Asih }=\frac{3-3}{3-2}=0 \\
& \text { Mensi Sriwahyuni } \quad=\frac{3-2}{3-2}=1
\end{aligned}
$$

Kriteria Kedisplinan:

$$
\begin{aligned}
& \text { Sukron Hutagaol }=\frac{2-1}{2-1}=1 \\
& \text { Surya Dermawan }=\frac{2-1}{2-1}=1 \\
& \text { Raimah }=\frac{2-1}{2-1}=1 \\
& \text { Kustini Asih }=\frac{2-2}{2-1}=0 \\
& \text { Mensi Sriwahyuni } \quad=\frac{2-2}{2-1}=0
\end{aligned}
$$

Berikut adalah hasil dari perhitungan normalisasi matriks:

Tabel 4. Normalisasi Matriks

\begin{tabular}{lcccccc}
\hline \multicolumn{1}{c}{ Alternatif } & C1 & C2 & C3 & C4 & C5 & C6 \\
\hline Sukron Hutagaol & 0,67 & 0 & 1 & 0,5 & 0 & 0 \\
Surya Dermawan & 0,33 & 1 & 1 & 0 & 1 & 1 \\
Raimah & 1 & 0 & 1 & 0,5 & 0 & 0 \\
Kustini Asih & 0,33 & 0 & 0 & 0 & 0 & 0 \\
Mensi Sriwahyuni & 0 & 1 & 0 & 1 & 0 & 1 \\
\hline
\end{tabular}

Selanjutnya menentukan nilai matriks normalisasi terbobot dimana hasil dari normalisasi matrik dikalikan dengan nilai bobot setiap kriteria sebagai berikut:

\section{Kriteria Tamatan Terakhir:}

Sukron Hutagaol $=0,67 * 0,2=0,13$

Surya Dermawan $=0,33 * 0,2=0,067$

Raimah $=1 * 0,2=0,2$

Kustini Asih $=0,33 * 0,2=0,67$

Mensi Sriwahyuni $=0 * 0,2=0$

\section{Kriteria Kedisplinan:}

Sukron Hutagaol $=1 * 0,2=0,2$

Surya Dermawan $=1 * 0,2=0,2$

Raimah $=1 * 0,2=0,2$

Kustini Asih $=0 * 0,2=0$

Mensi Sriwahyuni $=0 * 0,2=0$

Kriteria Absensi:

Sukron Hutagaol $=0 * 0,1=0$

Surya Dermawan $=1 * 0,1=0,1$

Raimah $=0 * 0,1=0$

Kustini Asih $=0 * 0,1=0$

Mensi Sriwahyuni $=0 * 0,1=0$

Berikut adalah hasil dari matriks normalisasi terbobot dapat dilihat pada tabel 5: 
Tabel 5. Matriks Normalisasi Terbobot

\begin{tabular}{lcccccc}
\hline Alternatif & C1 & C2 & C3 & C4 & C5 & C6 \\
\hline Sukron Hutagaol & 0,13 & 0 & 0,2 & 0,075 & 0 & 0 \\
Surya Dermawan & 0,067 & 0,25 & 0,2 & 0 & 0,1 & 0,1 \\
Raimah & 0,2 & 0 & 0,2 & 0,075 & 0 & 0 \\
Kustini Asih & 0,067 & 0 & 0 & 0 & 0 & 0 \\
Mensi Sriwahyuni & 0 & 0,25 & 0 & 0,15 & 0 & 0,1 \\
\hline
\end{tabular}

c) Menghitung nilai Utility Measure (S) dan Regret Measure (R) dengan menggunakan persamaan (2) dan (3). Utility Measure (S) :

Sukron Hutagaol $=0,13+0+0,2+0,075+0+0=0,4083$

Surya Dermawan $=0,067+0,25+0,2+0+0,1+0,1=0,7166$

Raimah $=0,2+0+0,2+0,075+0+0=0,475$

Kustini Asih $=0,067+0+0+0+0+0=0,0667$

Mensi Sriwahyuni $=0+0+0+0,15+0+0,1=0,5$

Regret Measure (R):

Sukron Hutagaol=0,2

Surya Dermawan $=0,25$

Raimah $=0,2$

Kustini Asih=0,0667

Mensi Sriwahyuni $=0,25$

d) Menghitung indeks VIKOR

Sukron Hutagaol $=\left(0,5^{*}((0,4083-0,0667)) /((0,7167-0,0667))\right)+\left((1-0,5)^{*}((0,2-0,0667)) /((0,25-0,0667))\right)$ $=0,6264$

Surya Dermawan $=(0,5 *((0,7166-0,0667)) /((0,7167-0,0667)))+((1-0,5) *((0,25-0,0667)) /((0,25-0,0667)))$ $=1$

Raimah $=(0,5 *((0,475-0,0667)) /((0,7167-0,0667)))+((1-0,5) *((0,2-0,0667)) /((0,25-0,0667)))=0,6777$ Kustini Asih= $(0,5 *((0,0667-0,0667)) /((0,7167-0,0667)))+((1-0,5) *((0,0667-0,0667)) /((0,25-0,0667)))=$ 0

Mensi Sriwahyuni $=\left(0,5^{*}((0,5-0,0667)) /((0,7167-0,0667))\right)+\left((1-0,5)^{*}((0,25-0,0667)) /((0,25-0,0667))\right)$ $=0,8333$

e) Melakukan pemeringkatan nilai $\operatorname{VIKOR}\left(Q_{i}\right)$

Tabel 6. Perangkingan

\begin{tabular}{clcc}
\hline No & \multicolumn{1}{c}{ Alternatif } & Q & Rank \\
\hline 1 & Sukron Hutagaol & 0,647 & 2 \\
2 & Surya Dermawan & 1 & 5 \\
3 & Raimah & 0,688 & 3 \\
4 & Kustini Asih & 0 & 1 \\
5 & Mensi Sriwahyuni & 0,867 & 4 \\
\hline
\end{tabular}

Dari tabel diatas dapat dilihat bahwa alternatif terbaik dengan nilai Q terkecil adalah Kustini Asih dengan nilai $\mathrm{Q}=0$, dan alternatif kedua yaitu Sukron Hutagaol dengan nilai $\mathrm{Q}=0,6264$, sedangkan urutan ketiga yaitu Raimah dengan nilai Q=0,6777. Dari hasil diatas maka yang dapat direkomendasikan berdasarkan perhitungan metode VIKOR adalah Kustini Asih, Sukron Hutagaol, dan Raimah.

\subsection{Hasil Percobaan Menggunakan Sistem}

Berisi hasil implementasi ataupun pengujian.

a) Hasil Perhitungan Analisa Data

Tampilan hasil perhitungan dapat dilihat pada Gambar 1. berikut. 
Journal of Computer System and Informatics (JoSYC)

Volume 3, No. 1, November 2021, Page 9-15

ISSN 2714-8912 (media online)

ISSN 2714-7150 (media cetak)

DOI 10.47065/josyc.v3i1.951

\section{Perhitungan}

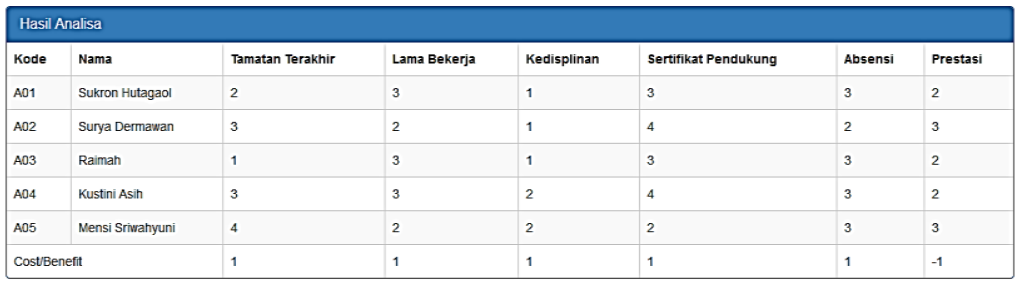

Gambar 1. Tampilan Hasil Perhitungan Analisa Data

b) Hasil Konversi Max And Min

Tampilan hasil perhitungan dapat dilihat pada Gambar 2. berikut.

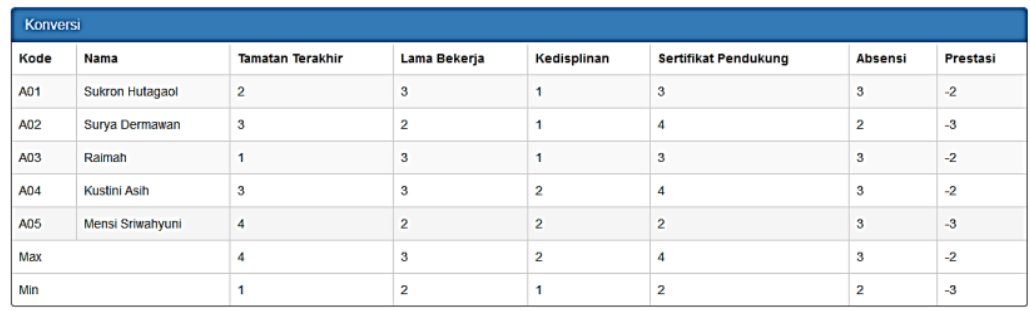

Gambar 2. Tampilan Hasil Perhitungan Nilai Perbandingan

c) Hasil Perhitungan Nij

Tampilan hasil perhitungan Nij dapat dilihat pada gambar 3. berikut.

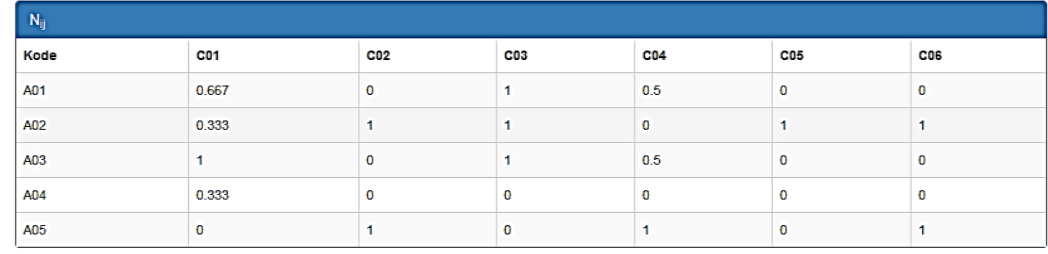

Gambar 3. Tampilan Hasil Perhitungan Nij

d) Hasil Perhitungan Nilai Terbobot

Tampilan hasil perhitungan nilai terbobot dapat dilihat pada gambar 4. berikut.

\begin{tabular}{|l|l|l|l|l|l|l|}
\hline Terbobot & C01 & C02 & C03 & C04 & C05 & 006 \\
\hline Kode & 0.133 & 0 & 0.2 & 0.075 & 0 & 0 \\
\hline A01 & 0.067 & 0.25 & 0.2 & 0 & 0.1 & 0.1 \\
\hline A02 & 0.2 & 0 & 0.2 & 0.075 & 0 & 0 \\
\hline A03 & 0.067 & 0 & 0 & 0 & 0 & 0 \\
\hline A04 & 0 & 0.25 & 0 & 0.15 & 0 & 0.1 \\
\hline A05 & & 0 & 0 & 0 \\
\hline
\end{tabular}

Gambar 4. Tampilan Hasil Perhitungan Nilai Terbobot

e) Hasil Perhitungan Nilai (S) Utilitas dan Ukuran Regret (R)

Tampilan hasil perhitungan nilai terbobot dapat dilihat pada gambar 5. berikut.

\begin{tabular}{|c|c|c|c|c|c|c|c|c|}
\hline Kode & c01 & $\mathrm{CO2}$ & $\mathrm{cos}$ & C04 & Co5 & c06 & $\mathrm{s}$ & $R$ \\
\hline A01 & 0.133 & 0 & 0.2 & 0.075 & 0 & 0 & 0.408 & 0.2 \\
\hline A02 & 0.067 & 0.25 & 0.2 & 0 & 0.1 & 0.1 & 0.717 & 0.25 \\
\hline A03 & 0.2 & 0 & 0.2 & 0.075 & 0 & 0 & 0.475 & 0.2 \\
\hline A04 & 0.067 & 0 & 0 & 0 & 0 & 0 & 0.067 & 0.067 \\
\hline A05 & 0 & 0.25 & 0 & 0.15 & 0 & 0.1 & 0.5 & 0.25 \\
\hline & & & & & & $\mathrm{s}^{*}$ & 0.717 & \\
\hline & & & & & & s- & 0.067 & \\
\hline & & & & & & $\mathrm{R}^{*}$ & & 0.25 \\
\hline & & & & & & R- & & 0.067 \\
\hline
\end{tabular}

Gambar 5. Tampilan Hasil Perhitungan Nilai Terbobot

f) Hasil Perhitungan Akhir Algoritma VIKOR

Tampilan hasil perhitungan dapat dilihat pada gambar 6. berikut. 


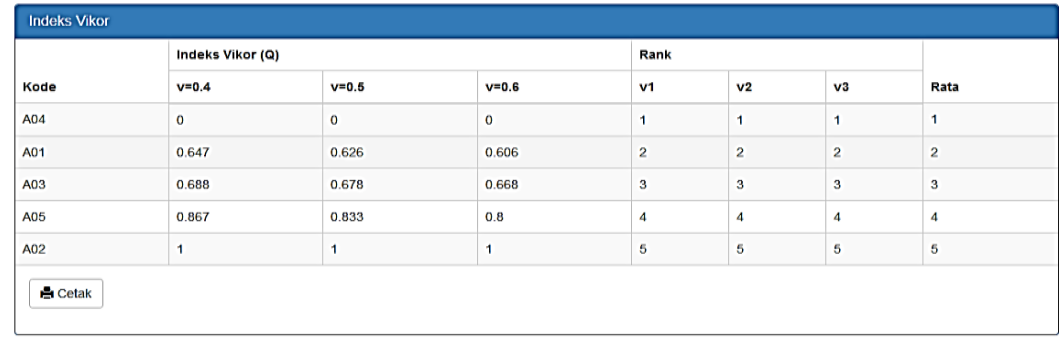

Gambar 6. Tampilan Hasil Perhitungan Algoritma VIKOR

\subsection{Pembahasan}

Sistem Pendukung Keputusan Pemilihan Guru Konseling Metode VIKOR di SMK TPI AL-HASANAH baik perhitungan secara manual maupun secara komputerisasi menunjukkan hasil yang sama, yaitu alternatif $\mathrm{A}_{4}$ merupakan alternatif terbaik. Berikut adalah hasil yang diperoleh menggunakan komputerisasi dengan aplikasi berbasis VB.

Tabel 7. Perhitungan Algoritma Menggunakan Komputerisasi

\begin{tabular}{clcc}
\hline No & \multicolumn{1}{c}{ Alternatif } & Q & Rank \\
\hline 1 & Sukron Hutagaol & 0,647 & 2 \\
2 & Surya Dermawan & 1 & 5 \\
3 & Raimah & 0,688 & 3 \\
4 & Kustini Asih & 0 & 1 \\
5 & Mensi Sriwahyuni & 0,867 & 4 \\
\hline
\end{tabular}

Pengujian perhitungan manual yang diimplementasikan kedalam Sertifikat Pendukung komputerisasi bertujuan untuk melihat kesesuian hasil yang diperoleh antara perhitungan secara manual maupun secara komputerisasi. Jika hasil yang diperoleh menggunakan komputerisasi sesuai dengan perhitungan manual, maka kedepannya sistem yang dibangun mampu beroperasi di instansi terkait guna membantu proses penentuan penentuan guru konseling.

\section{KESIMPULAN}

Berdasarkan hasil dari penelitian yang dilakukan maka dapat di simpulkan metode VIKOR dapat diterapkan dalam pengambilan keputusan oleh pihak sekolah untuk melakukan pemilihan guru konseling di SMK TPI AlHasanah Pematang Bandar. Metode VIKOR juga membangun sebuah aplikasi Visual Basic dengan hasil pengujian yang sama dengan data secara manual yang dapat digunakan dalam pemilihan guru konseling di SMK TPI Al-Hasanah Pematang Bandar. Dari hasil pengolahan data secara manual dan system diperoleh hasil yang sama dengan mengambil 5 sampel yaitu Sukron Hutagaol, Surya Dermawan, Raimah, kustini Asih dan juga Mensi Sriwahyuni. Dimana yang menempati posisi pertama kustini Asih dengan nilai Q terkecil yaitu $\mathrm{Q}=0$, Sukron Hutagaol dengan nilai $\mathrm{Q}=0,647$, Raimah dengan nilai $\mathrm{Q}=0,688$, Mensi Sriwahyuni dengan nilai $\mathrm{Q}=0,867$ dan Surya Dermawan dengan dengan nilai $\mathrm{Q}=1$

\section{REFERENCES}

[1] N. Rofiqo, A. P. Windarto, and A. Wanto, "Penerapan Metode VIKOR Pada Faktor Penyebab Rendahnya Minat Mahasiswa Dalam Menulis Artikel Ilmiah,” Semin. Nas. Sains Teknol. Inf., 2018.

[2] T. Limbong et al., Sistem Pendukung Keputusan: Metode \& Implementasi. Medan: Yayasan Kita Menulis, 2020.

[3] M. W. P. Agatmadja and A. Suri, "Penerapan Metode VIKOR Dalam Pemilihan Calon Peserta Olimpiade Olahraga Siswa Nasional ( O2SN ),” vol. 5, no. 2, pp. 91-96, 2018.

[4] M. Sianturi, S. Wulan, Suginam, Rohminatin, and Mesran, "Implementasi Metode VIKOR Untuk Menentukan Bahan Kulit Terbaik Dalam Pembuatan Ikat Pinggang,” J. Ris. Komput., vol. 5, no. 1, pp. 56-60, 2018.

[5] J. Papathanasiou and N. Ploskas, Multiple Criteria Decision Aid: Methods, Examples and Python Implementations. Springer, 2018.

[6] M. Mesran et al., "The VIKOR Method to Support the Effectiveness of Decisions in Determining Work Incentive Recipients," in Journal of Physics: Conference Series, 2019, vol. 1175, no. 1.

[7] N. S. Damanik, E. Irawan, M. R. Lubis, A. P. Windarto, and D. Suhendro, "Analisis Metode Vise Kriterijumska Optimizajica I Kompromisno Resenje ( VIKOR ) dalam Merekomendasikan Pupuk Terbaik bagi Produktivitas Tanaman Kelapa Sawit,” J. Inf. Syst. Res., vol. 2, no. 1, pp. 47-54, 2020.

[8] N. Sutrikanti, H. Situmorang, Fachrurrazi, H. Nurdiyanto, and M. Mesran, "Implementasi Pendukung Keputusan Dalam Pemilihan Calon Peserta Cerdas Cermat Tingkat SMA Menerapkan Metode VIKOR,” JURIKOM (Jurnal Ris. Komputer), 2018.

[9] S. Pendukung et al., "MENGGUNAKAN METODE SIMPLE ADDITIVE WEIGHTING PADA PERUSAHAAN Tugas Akhir Fakultas Ilmu Komputer , Universitas Dian Nuswantoro Semarang Tugas Akhir Fakultas Ilmu Komputer , Universitas Dian Nuswantoro Semarang," pp. 1-9, 2014. 
Journal of Computer System and Informatics (JoSYC)

Volume 3, No. 1, November 2021, Page 9-15

ISSN 2714-8912 (media online)

ISSN 2714-7150 (media cetak)

DOI 10.47065/josyc.v3i1.951

[10] M. M. Ahp-topsis and H. Lumaksono, "Sistem Pendukung Keputusan untuk Menentukan Alat Tangkap yang Sesuai bagi Nelayan di Madura," vol. 1509, pp. 1-6, 2017.

[11] B. Simamora, "Rancang Bangun Sistem Rekomendasi Televisi LED Dengan Metode Vikor Berbasis Web," vol. IX, no. 1, pp. 42-49, 2017. 